\title{
PASOS HACIA UNA TEORÍA CONSTRUCTIVISTA Y CONEXIONISTA DEL RAZONAMIENTO JUDICIAL EN LA TRADICIÓN DEL DERECHO ROMANO-GERMÁNICO*
}

\author{
Enrique CÁCERES**
}

Resumen:

El objetivo de este ensayo es presentar un modelo teórico del razonamiento judicial que pueda integrar de manera satisfactoria las explicaciones parciales ofrecidas en tres distintos paradigmas de investigación teórica: la filosofía del derecho, la epistemología jurídica y la inteligencia artificial aplicada al derecho.

Este modelo surge de la aplicación de algunos métodos de elicitación y representación del conocimiento. Y emplea la teoría de las redes neurales como una metáfora teórica a fin de generar sus propias explicaciones y representaciones visuales.

El estatus epistemológico del modelo es de corte constructivista, y se encuentra en la línea de las tendencias de investigación contemporánea dentro de la psicología cognitiva, la cual plantea que el razonamiento ju-

* En este artículo presento avances de mi investigación posdoctoral dentro del programa de "Derecho y Cognición", bajo la tutoría de la doctora Sandra Castañeda en el Laboratorio de Desarrollo Cognitivo y Aprendizaje Complejo de la Facultad de Psicología de la UNAM. La investigación referida está siendo financiada por el Conacyt. Me encuentro muy agradecido con el centro SCRIPT de la Facultad de Derecho de la Universidad de Edimburgo, en donde tuve la oportunidad de culminar el artículo. Disfrute en sus instalaciones de un excelente ambiente académico durante el mes que duró mi estancia como profesor visitante. Quiero agradecer particularmente al profesor Graeme Laurie, director del SCRIPT, así como al profesor Burkhard Schafer, co-director de dicho centro y co-fundador del Joseph Bell Center for Legal Reasoning and Forensic Statistics.

** Investigador en el Instituto de Investigaciones Jurídicas de la UNAM, encacer@hotmail.com. 


\title{
ENRIQUE CÁCERES
}

dicial puede ser entendido de mejor manera si asumimos un enfoque coherentista y conexionista.

Palabras clave:

Modelo coherentista-conexionista del razonamiento judicial, redes neurales y derecho, epistemología jurídica, razonamiento en materia probatoria.

\begin{abstract}
:
The aim of this paper is to provide a theoretical model of judicial reasoning that satisfactorily integrates the partial explanations offered by three different theoretical research paradigms: Philosophy of Law, Legal Epistemology, and Artificial Intelligence and Law.

The model emerges from the application of knowledge elicitation and knowledge representation methods. The model employs the theory of neural networks as a theoretical metaphor in order to generate its explanations and its visual representations.

The epistemological status of the model is of a constructivist stripe. It is in line with contemporary research tendencies within cognitive psychology that propose that judicial reasoning may be better understood if we assume a coherentist and a connectionist approach.
\end{abstract}

Keywords:

Coherentist-Connectionist Model of Judicial Reasoning, Legal Neural Networks, Legal Epistemology, Reasoning about Legal Evidence. 
SUMARIO: I. Introducción. II. El problema. III. La propuesta teórica. IV. El enfoque constructivista-conexionista: un nuevo punto de partida. V. El modelo mental conexionista del razonamiento judicial romanogermánico. VI. El caso Hattori. VII. Discusión. VIII. Futuras investigaciones. IX. Justificación social.

\section{INTRODUCCIÓN}

Para Hart, las preguntas recurrentes en la teoría del derecho pueden ser respondidas adecuadamente si se concibe al derecho como la unión de reglas primarias y secundarias. Dentro de estas últimas se encuentran las de adjudicación empleadas por los jueces para decidir los casos que se someten a su consideración.

Esto implica que una adecuada explicación del razonamiento judicial es de suma importancia para una clara comprensión de una de las instituciones jurídicas más importantes.

Sin embargo, dicha explicación dista de ser homogénea. Al contrario, existen una multiplicidad de explicaciones provenientes de diversas comunidades teóricas, cada una de las cuáles da cuenta de algunos aspectos de este fenómeno, sumamente complejo, desde sus presupuestos conceptuales y metodológicos.

Las comunidades que considero más importantes y que tomaré como punto de referencia en este trabajo son: la de la filosofía del derecho, la de la epistemología jurídica e, indirectamente, la de la inteligencia artificial aplicada al derecho (IA y D).

Cada una puede ser caracterizada brevemente de la manera siguiente: Dentro de la filosofía del derecho hay dos posturas básicas: quienes sostienen que el razonamiento judicial es silogístico (tradición romano germánica) y quienes afirman que los jueces deciden con base en procesos psicológicos subjetivos (realismo americano). Dentro de la epistemología jurídica se encuentra la postura de Larry Laudan. Para este autor, quien circunscribe sus reflexiones 
al derecho penal, el objetivo de la epistemológica jurídica consiste en evaluar los procesos jurídicos en tanto sistemas de investigación tendentes a la obtención de creencias verdaderas, con los mismos parámetros que otros sistemas de investigación, particularmente los científicos. ${ }^{1}$ Dentro de la propia epistemología jurídica, otra comunidad asume que el uso de términos vagos tales como "más allá de toda duda razonable" o "con base en la convicción íntima" usados por las reglas de adjudicación, producen arbitrariedad e irracionalidad en las decisiones de los jueces. Este problema, asumen, puede resolverse importando al derecho métodos de investigación que han probado su utilidad en la ciencia. ${ }^{2}$ Por último, la $\mathrm{IAD}$ ha centrado su atención en la lógica no monotónica, los procesos argumentativos dialógicos y derrotantes, su relación con narrativas, razonamiento abductivo e inferencia a la mejor explicación. ${ }^{3}$

1 Laudan, Larry, Truth, Error, and The Criminal Law, an Essay in Legal Epistemology, Cambridge University Press, 2006; véase también Laudan, Larry, The Social Contract and the Rules of Trial: Re-Thinking Procedural Rules; Deadly Dilemmas; Is Reasonable Doubt Reasonable?; The Elementary Epistemic Arithmetic of Criminal Justice; Strange Bedfellows: Inference to the Best Explanation and the Criminal Standard of Proof; Legal Epistemology: The Anomaly of Affirmative Defenses; The Presumption of Innocence: Material or Probatory?; Deadly Dilemmas II: Bail and Crime; Need Verdicts Come in Pairs?; Taking the Ratio of Differences Seriously: The Multiple Offender and the Standard of Proof, or, Different Strokes for Serial Folks; Re-Thinking the Criminal Standard of Proof: Seeking Consensus About the Utilities of Trial Outcomes; y "Aliados extraños: la inferencia a la mejor explicación y el estándar de prueba penal”, Problema, Anuario de Filosofía y Teoria del Derecho, México, núm. 1, 2007, http://www.juridicas.unam. mx/publica/librev/rev/filotder/cont/1/pr/pr10 .$p d f$.

2 Taruffo, Michele, La prueba de los hechos, 2a. ed., Trotta, 2006; id., La prueba, Madrid, Marcial Pons, 2008; Ferrer, Jordi, Prueba y verdad en el derecho, 2a. ed., Madrid, Marcial Pons, 2005; id., La valoración racional de la prueba, Madrid, Marcial Pons, 2007; Gascón, Marina, Los hechos en el derecho. Bases argumentales de la prueba, 2a. ed., Madrid, Marcial Pons, 2004.

3 Algunos de los trabajos más representativos de esta comunidad son los siguientes: Walton, Douglas et al., Argumentation Schemes, Cambridge, Cambridge University Press, 2008; Walton, Douglas Argumentation Methods for Artificial Intelligence in Law, Berlín, verano, Lecture Notes in Artificial Intelligence Series, 2005; Walton, Douglas, Legal Argumentation and Evidence, University Park, Pa., Penn State Press, 2002; Walton, Douglas, “Argument Visualization Tools for Corroborative Evidence" (Proceedings of the 2nd International Conference on Evidence Law and Forensic Science, Institute of Evidence Law and Forensic Science, Beijing, 2009, 32-49); Walton, Douglas y Gordon, Thomas F., "Legal Reasoning with Argumenta- 
Un análisis comparado de los explanans de dichas tradiciones arroja lo siguiente: la filosofia del derecho se interesa por la relación entre razonamiento judicial y normas, ya sea como premisas, o para negar su utilidad real, pero no en problemas relativos a la evidencia ni a la argumentación dialógica; la epistemología jurídica pone énfasis en las proposiciones de hechos y la evidencia, pero no en la argumentación dialógica y las narrativas; la comunidad de la IAD presta poca atención a los problemas normativos y se centra en proposiciones de hechos, así como en los argumentos y las narrativas, pero no se ocupa de problemas conceptuales de la epistemología jurídica. Algunos de sus trabajos pueden criticarse porque sus consideraciones acerca de la abducción e inducción a la mejor explicación ignoran el papel del estándar de prueba como medio para distribuir errores, diferente al 50\% de falsas absoluciones o falsas condenas. Por otra parte, sus análisis acerca de narrativas múltiples para un mismos caso se basan en eventos que presuponen normas fijas, sin tomar en cuenta que, dada la función constitutiva de las normas jurídicas, los hechos jurídicos son hechos institucionales dependientes de las normas y que la definición de los mismos es el resultado de un equilibrio reflexivo entre posibles normas a aplicar, los propios enunciados sobre hechos, evidencias y teorías dogmáticas. El modelo atomista de la evidencia del que parten oculta profundos problemas relativos a la adminiculación probatoria.

tion Schemes" (12th International Conference on Artificial Intelligence and Law, Hafner, Carole D. (ed.), Nueva York, Association for Computing Machinery, 2009, 137-146); Walton, Douglas, "Visualization Tools, Argumentation Schemes and Expert Opinion Evidence in Law", Law, Probability and Risk, 6, 2007, 119-140; Prakken, Henry, "Formalising Ordinary Legal Disputes: a Case Study", Artificial Intelligence and Law 16, 2008, 333-359; Prakken, Henry, "A Formal Model of Adjudication Dialogues", Artificial Intelligence and Law 16, 2008, 305-328; Gordon, Tom, Prakken, Henry \& Walton, Douglas, "The Carneades Model of Argument and Burden of Proof", Artificial Intelligence 171, 2007, 875-896; Bex, F. J. et al., "Sense-Making Software for Crime Investigation: How to Combine Stories and Arguments?", Law, Probability \& Risk 6, 2007, 145-168; Prakken, Henry, “Analysing Reasoning about Evidence with Formal Models of Argumentation", Law, Probability \& Risk 3: 1, 2004, 33-50; Floris, Bex et al., "Towards a Formal account of Reasoning about Evidence: Argumentation Schemes and Generalisations", Artificial Intelligence and Law 11, 2003, 125-165. 


\section{EL PROBLEMA}

¿Cómo integrar explicaciones tan diferentes acerca de lo que habría que asumir es el mismo explanandum?, ¿cuál es, si es que la hay, la estructura implicada por las diferentes teorias?, ¿qué falta por desarrollar para tener una mejor comprensión del razonamiento judicial?

\section{LA PROPUESTA TEÓRICA}

La idea central de este trabajo es que ha hecho falta una reflexión descriptiva y naturalizada sobre el razonamiento judicial. Hasta el momento las discusiones han sido de otra indole: especulativas (filosofia del derecho); evaluativas (Laudan); prescriptivas (Ferrer, Taruffo, etcétera,); lógicas (IAD).

En este trabajo presento una versión muy preliminar de lo que sería dicho modelo que, considero, debería ser presupuesto por los trabajos de las demás comunidades, en los siguientes términos: una evaluación epistemológica es más acertada si considera el uso pragmático del sistema de investigación y no únicamente reglas desconectadas de las prácticas comunitarias de sus usuarios; no es posible descalificar al razonamiento judicial de irracional a partir del análisis descontextualizado de términos vagos, sin antes tener un modelo de dicho razonamiento sobre el cual realizar las críticas; por último, una explicación sobre argumentos y narrativas que ignora la dinámica de los esquemas cognitivos usados por los jueces lleva a la sobre-simplificación.

\section{El ENFOBUE CONSTRUCTIVISTA-CONEXIONISTA:}

UN NUEVO PUNTO DE PARTIDA

\section{La experiencia de "Expertius"}

Expertius es el nombre de un sistema experto para la ayuda a la decisión judicial elaborado en el Instituto de Investigaciones Jurídicas de la Universidad Nacional Autónoma de México. Su desarrollo teórico adoptó la teoría ato- 
mista de la evidencia y el modelo de cascada que implica que los pesos probatorios de las evidencias se transfieren a las proposiciones de hechos que se pretende demostrar. ${ }^{4}$

Sin embargo, durante los trabajos de elicitación del conocimiento surgieron una serie de fenómenos cognitivos de gran trascendencia que han pasado desapercibidos por los trabajos sobre el razonamiento judicial de las comunidades previamente referidas. Algunos de esos fenómenos quedaron conceptualizados de la manera siguiente:

1) Tendencia determinante. Los jueces deciden con base a estructuras heurísticas previamente configuradas en memoria a largo plazo, que son reactivadas en la memoria de trabajo en cada caso concreto. No es cierto que cada caso sea resuelto de manera individual con base en sus propios méritos.

2) Profecía auto-cumplida. La activación de esquemas heurísticos robustecidos por la práctica lleva a que los

4 Enrique Cáceres, "Reporte Técnico Final del proyecto 42163-S Sistemas expertos de ayuda a la decision judicial"; Enrique Cáceres, "EXPERTIUS: A Mexican Judicial Decision-Support System in the Field of Family Law", Proceedings of the

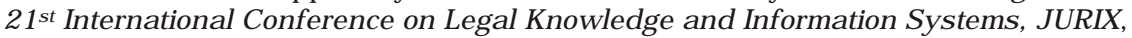
2008; Cáceres, Enrique, "Cognitive Legal Constructivism and Artificial Intelligence Applied to Law (CONACYT-IIJ Project: Expert Systems for the Assistance in Judicial Rulings)" (Noriega, P., Regulating Virtual Interactions, Trends in Legal Knowledge, the Semantic Web and the Regulation of Electronic Social Systems, Casanovas, P. et al., (eds.), México, Institute of Law and Technology (UAB)-UNAM, Instituto de Investigaciones Jurídicas, forthcoming; Cáceres, Enrique, "A Constructivist Model for the Judicial Determination of Facts", Proceedings of the Eleventh International Conference on Artificial Intelligence and Law, 2007; Cáceres, Enrique, "Juridical Constructuvism, Artificial Intelligence, and E-Justice, The Mexican IIJ-Conacyt Project", Workshop on The Role of Legal Knowledge in E-Government, Proceedings of the Eleventh International Conference on Artificial Intelligence and Law, 2005; Cáceres, Enrique, "Cognition, Epistemology, and Reasoning about Evidence within the Legal Domain”, Problema, Anuario de Teoría y Filosofía del Derecho, México, núm. 2, 2008, http://www.juridicas.unam.mx/publica/librev/rev/filotder/cont/2/pr/pr 11.pdf; Cáceres, Enrique, "Constructivismo jurídico fáctico y elicitación del conocimiento en el Proyecto Conacyt-IIJ-CCADET-STJT", La ciencia del derecho procesal constitucional. Estudios en homenaje a Héctor Fix-Zamudio en sus cincuenta años como investigador del derecho, t. XI, Justicia, federalismo y derecho constitucional, 2008, http://www.bibliojuridica.org/libros/6/2563/21.pdf); Cáceres, Enrique, "Inteligencia artificial, derecho E-Justice (el Proyecto IIJ-Conacyt", Boletín Mexicano de Derecho Comparado, México, 116, 2006, http://www.juridicas.unam. mx/publica/rev/boletin/cont/116/inf/inf12.htm). 
jueces tomen "pre-decisiones" que determinan su sentencia. Es decir, con base en esquemas previos, frecuentemente los jueces saben de antemano qué buscar y qué van a encontrar al final de la decisión. La coherencia de la decisión final suele ser resultado del estado global de sus esquemas heurísticos más que del caso en sí.

3) Evaluación interdependiente de la evidencia. El peso probatorio de las evidencias y la forma en que estas son interconectadas, frecuentemente obedece a las decisiones pre-determinadas, las cuales, en muchos casos, incluyen creencias de sentido común que alteran la aplicación "neutral" del derecho.

4) Refracción cognoscitiva. Cuando los esquemas han sido sistemáticamente robustecido se convierten en automatismos que llegan a impedir que sea filtrada información relevante para distinguir y tratar diferente un caso respecto a otros de la misma clase.

5) Individualización cognoscitiva. Cuando cierto tipo de casos no activa esquemas suficientemente robustecidos o las prácticas de la comunidad no han sido adecuadamente compartidas, casos análogos suelen ser resueltos de maneras diversas, o con argumentos que, aunque plausibles, son muy diferentes entre sí. Esto ocurre, por ejemplo, cuando recién ha entrado en vigor una reforma legislativa o hay un cambio de jurisprudencia.

2. Una tercer vista a la caja negra:

las investigaciones experimentales de Dan Simon

y su modelo coherentista-conexionista ${ }^{5}$

Posteriormente a la conclusión de Expertius, se identificó una investigación experimental realizada por Dan Simon

5 Simon, Dan "A Third View of the Black Box: Cognitive Coherence in Legal Decision Making”, The University of Chicago Law Review, 2004. 
sobre jurados, con resultados altamente compatibles con los que se habian obtenido con Expertius.

Algunos de ellos son los siguientes:

1) Dos grupos experimentales ajustaron el mismo conjunto de evidencias de tal suerte que fueran coherentes con su calificación inicial de hechos en términos de culpabilidad o inocencia.

2) Los desplazamientos coherentistas (cambios en el estado del sistema) realizados durante un proceso de toma de decisión son determinados por los estados anteriores.

3) Los desplazamientos coherentistas operan a nivel inconsciente, lo que invita a revisar profundamente el supuesto control racional y consciente de las decisiones judiciales.

4) Cada desplazamiento coherentista impacta en la configuración del sistema heurístico global.

5) Elementos que podrían considerarse periféricos, pueden tener una gran influencia en la decisión final, como ocurre con las creencias subjetivas.

6) Las motivaciones y actitudes del sujeto juegan un papel muy importante en la decisión final. Un grupo de sujetos con actitudes pro-pena de muerte se mostro notoriamente proclive a declaraciones de culpabilidad, mientras que sujetos anti-pena de muerte a declaraciones de inocencia.

7) Las estructuras coherentes son volátiles, tienden a desaparecer con el tiempo si no son sistemáticamente reforzadas.

3. Conexionismo, jurados (tradición anglosajona) y jueces (tradición romano-germánica)

A pesar de que la investigación de Simon estuvo centrada en jurados, puede asumirse que sus resultados también son predicables de los jueces de la tradición romano-germá- 
nica. Sin embargo, esta tradición implica una serie de diferencias cognitivas relevantes derivadas de sus presupuestos positivistas y el importante papel que juegan en ella la legislación, así como las teorías dogmáticas (diferencias a nivel de creencias). Por otra parte, dado que escapa a sus objetivos teóricos, el trabajo de Simon no se ocupa del problema de la visualización que tanta relevancia tiene en el ámbito de la IAD. Lo que a continuación presento (en términos de metáfora teórica) es un modelo descriptivo de los procesos cognitivos de jueces de tradición romano-germánica que llamaré "modelo mental constructivista-conexionista del razonamiento judicial (MMCCRJ)", o, de manera más abreviada "modelo mental conexionista del razonamiento judicial (MMCJ). Tomaré como dominio de referencia al derecho penal; sin embargo, asumo que las bases teóricas generales del modelo son exportables a cualquier otro dominio jurídico dentro de la misma tradición. Dentro del derecho penal se asume (sin haberse mostrado aún) que dicho modelo puede ser instanciado con cualquier delito.

\section{El MODELO MENTAL CONEXIONISTA DEL RAZONAMIENTO JUDICIAL ROMANO-GERMÁNICO}

\section{Modelos mentales}

El término "modelo mental" es usado por primera vez por Kenneth Craik en 1943. ${ }^{6}$

Algunas definiciones de la expresión son: "representaciones mentales del mundo real o situaciones imaginarias"; "representaciones de la realidad que la gente usa para comprender un fenómeno específico"; "son representaciones psicológicas del mundo real o situaciones hipotéticas o imaginarias"; "es una explicación acerca de los procesos de pensamiento de alguien acerca de la forma en que funciona el mundo real"; "son modelos declarativos acerca de la for1943).

6 Craik, Kenneth, The Nature of Explanation, Cambridge University Press, 
ma en que está organizado el mundo y muchos contienen conocimiento general o abstracto y casos concretos". ${ }^{7}$

Todos tenemos modelos mentales acerca del mundo en el que vivimos, acerca de la historia patria, sus héroes y sus episodios; de lo que es una catedral gótica o, más específicamente, Notre Dame; de la distribución de los espacios en nuestra casa, etcétera. Los modelos mentales son las cartas de navegación que determinan la manera en que interactuamos con el mundo y los demás.

Las teorías científicas también son modelos mentales de carácter abstracto que permiten comprender, predecir y manipular al mundo.

Desde la perspectiva del modelo conexionista de la memoria, los elementos simbólicos constitutivos de los modelos mentales (una imagen, por ejemplo) son estructuras supervenientes a patrones de conectividad neuronal y las funciones cerebrales que involucran tanto a la amígdala como al hipocampo y al córtex. Esto significa que las emociones también juegan un papel fundamental en la elaboración de dichos modelos.

Como se indica en alguna de las definiciones previas, los modelos mentales pueden incluir tanto conocimiento abstracto, como casos concretos, lo cual involucra tanto a la memoria episódica (experiencias concretas), como a la memoria semántica (estructuras abstractas); tanto a la memoria a largo plazo (conocimiento heurístico) como a la memoria de trabajo (solución de casos concretos). Modelos de esta clase son, más que un estado, un proceso continuo de acoplamientos estructurales entre esquemas abstractos y experiencias. ${ }^{8}$

7 Van Merriënboer, J. J. G et. al., "Blueprints for Complex Learning: The 4C/ID-model", Educational Technology, Research and Development, 50 (2), 2002, pp. 39-64.

8 Peñalosa, E. y Castañeda, S., "El Análisis Cognitivo de Tareas, Base para el Diseño de Instrumentos de Evaluación en el Aprendizaje en Línea”, Revista Iberoamericana de Evaluación Educativa, 2o.(1), 2009, pp. 162-185. http://www.rinace. net/riee/numeros/vol2-num1/art9.pdf. Castañeda, S. (2002), "A Cognitive Model for Learning Assessment”, International Journal of Continuing Engineering Education and Life-long Learning, 12 (1-4), 94/106.Reino Unido:UNESCO. 
Los modelos mentales pueden ser de diferentes tipos: conceptuales, estructurales, causales (o procedurales); o complejos, es decir, integrados por los tres tipos anteriores.

Para los efectos de este trabajo, estipulo el término "modelo mental" de la siguiente manera: denota a "Todo sistema complejo de representaciones mentales, así como a las reglas de generación que las producen”.

Con respecto al estatus epistemológico de dichas representaciones, pueden comprender imágenes mentales o proposiciones, acerca de eventos reales, imaginarios o constituidos performativamente; pertenecientes al "mundo externo", a mundos posibles o a la realidad socialmente construida; de fenómenos pasados, presentes o futuros; implícitos o explícitos; de conocimiento experto o conocimiento ordinario, etcétera.

El tipo de modelo mental que me propongo elaborar involucra tanto a representaciones proposicionales (constructos normativos), así como a imágenes mentales y eventos constituidos pertenecientes a la realidad socialmente construida a través del discurso jurídico, así como a conocimiento experto tanto explícito como implícito, abstracto y heurístico.

En cuanto a si el modelo mental es de tipo común o es abstracto, científico o de sentido común, se trata de un modelo mixto que involucra conceptos abstractos correspondientes al carácter general de las normas jurídicas, pseudocientífico en el sentido de que incorpora elementos de la teoría del derecho y de sentido común en tanto muchas de las creencias involucradas en las decisiones jurídicas presuponen este tipo de creencias.

Con relación a la arquitectura del modelo mental, constituye un modelo complejo constituido por conceptos de diferentes clases, relaciones entre los mismos y reglas causales entre ellos. De esta arquitectura (que justifica el uso de la metáfora neuronal) me ocuparé a continuación. 


\section{Conexionismo}

Como es ampliamente conocido, los dos paradigmas fundamentales de las ciencias cognitivas están construidos sobre la base de metáforas teóricas: una sobre las computadoras y el otro sobre la arquitectura neuronal del cerebro.

Para los efectos de este trabajo, se considera un modelo conexionista artificial, cuya definición es la siguiente:

Definición formal: “...Una red neuronal es un grafo dirigido, con las siguientes propiedades:

a. A cada nodo $i$ se asocia una variable de estado $x i$.

b. A cada conexión $(i, j)$ de los nodos $i$ y $j$ se asocia un peso wij $\in \mathrm{R}$.

c. A cada nodo $i$ se asocia un umbral $\theta i$.

d. Para cada nodo $i$ se define una función $f i(x j$, wij, $\theta i$ ),que depende de los pesos de sus conexiones, del umbral y de los estados de los nodos $j$ a el conectados. Esta función proporciona el nuevo estado del nodo."

De manera informal, McClelland define a una red neuronal o conexionista como un sistema formado por los siguientes elementos:

i) Un conjunto de procesadores elementales o neuronas artificiales.

ii) Un patrón de conectividad o arquitectura.

iii) Una dinámica de activaciones.

iv) Una regla o dinámica de aprendizaje.

v) El entorno donde opera.

A continuación se procede a ilustrar cada uno de estos puntos:

i) La representación gráfica de una neurona artificial es la siguiente: 


\section{ENRIQUUE CÁCERES}

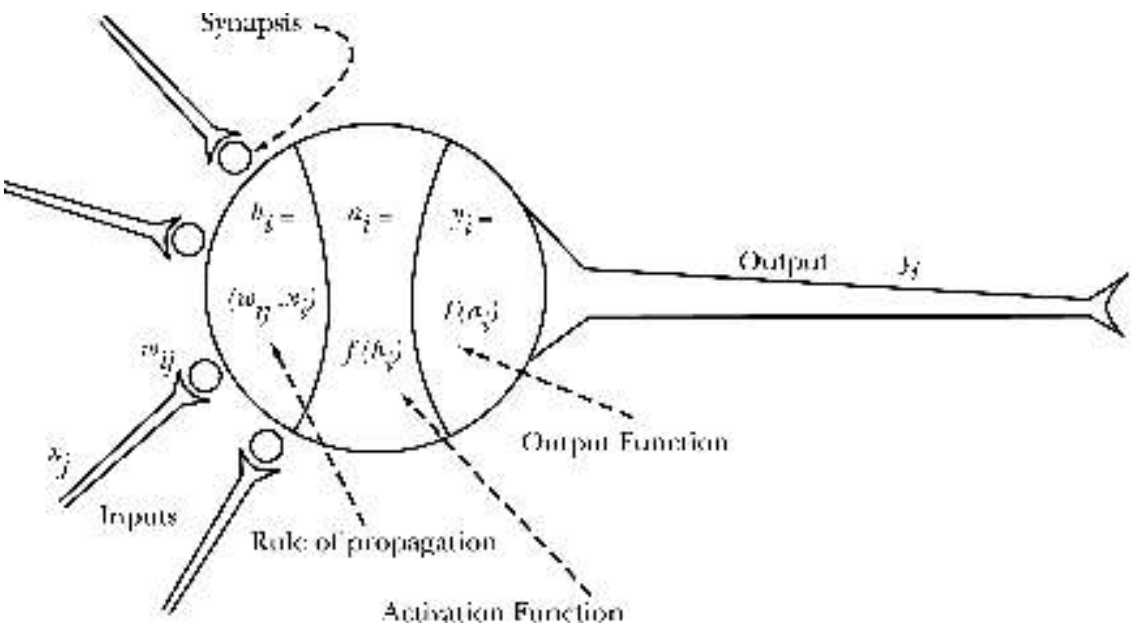

ii) El patrón de conectividad neuronal se ilustra con las siguientes gráficas:

- La conexión entre una neurona pre-sináptica (j) y una post-sináptica (i):

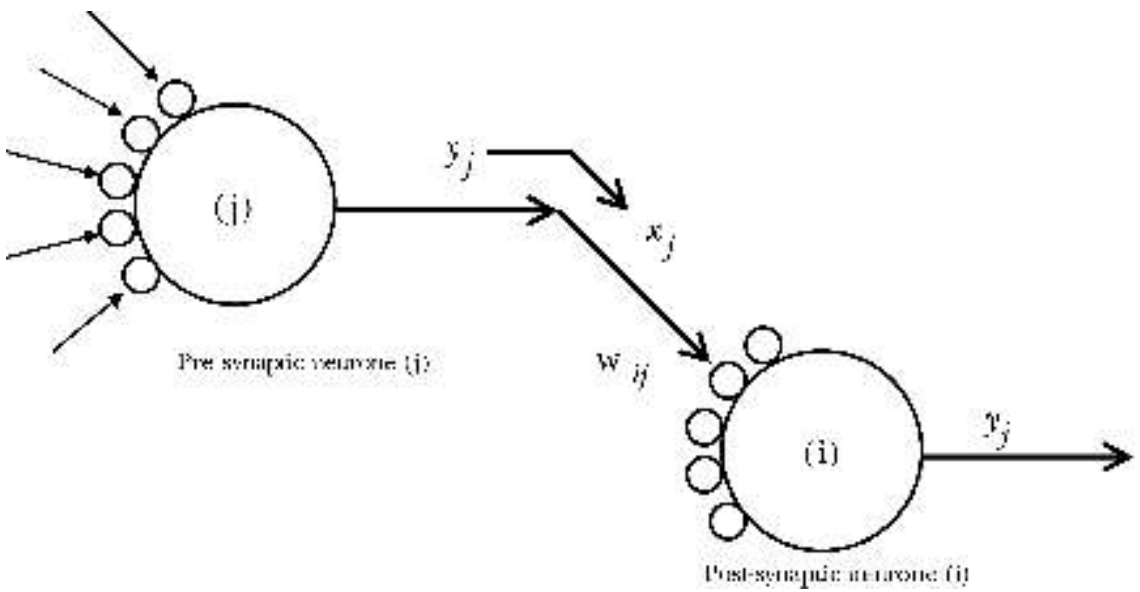


- La representación de una neurona con múltiples entradas pre-sinápticas y una salida post-sináptica:

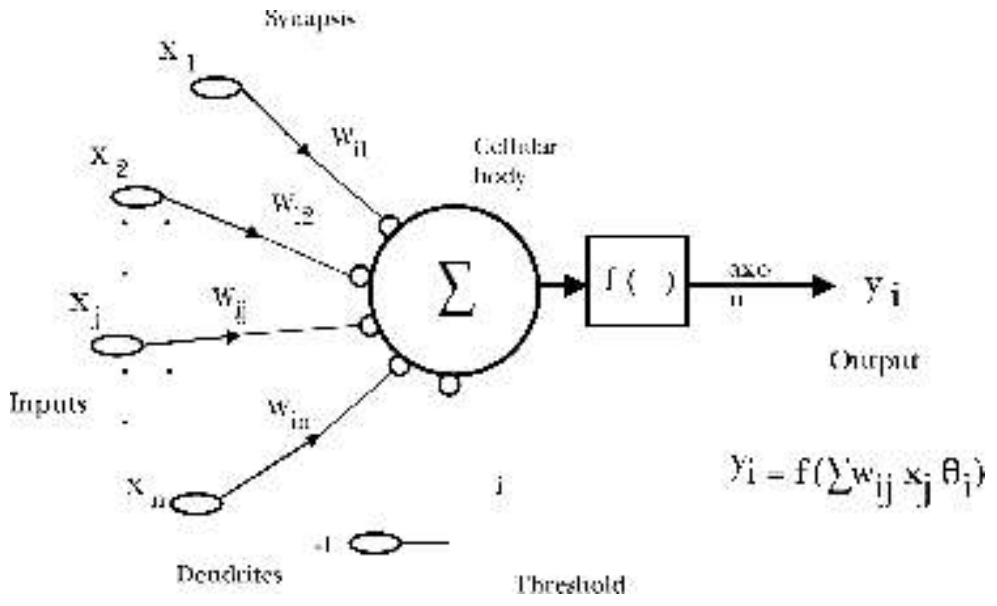

- La arquitectura de una red neuronal está constituida necesariamente por dos capas: una capa de entrada que integra a las neuronas sin sinapsis entrantes y una neurona de salida que incluye a las neuronas sin sinapsis saliente (Vid., p. 24). Las neuronas de entrada son las que reciben los inputs del entorno y las de salida las que proporcionan el output que puede activar conductas motoras. Su representación gráfica es la siguiente:

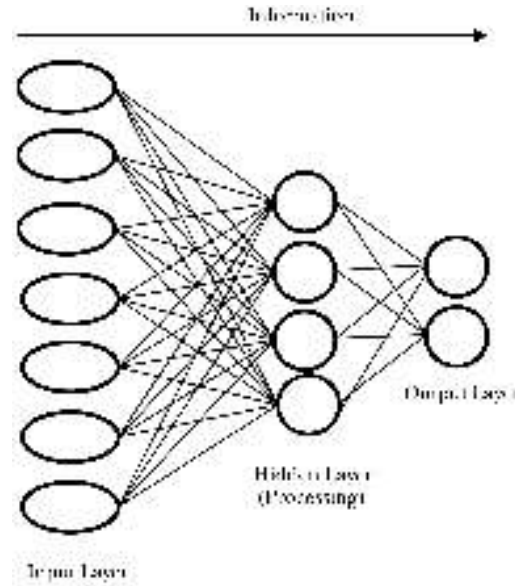


- Los patrones de conectividad pueden operar de manera uni y bidireccionalmente, intra e intercala y de manera recurrente.

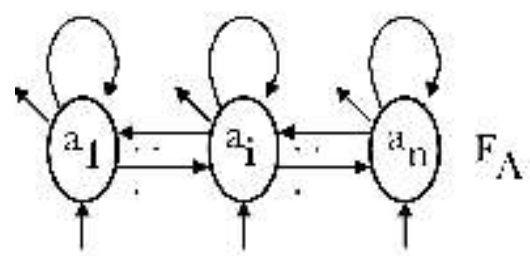

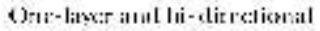

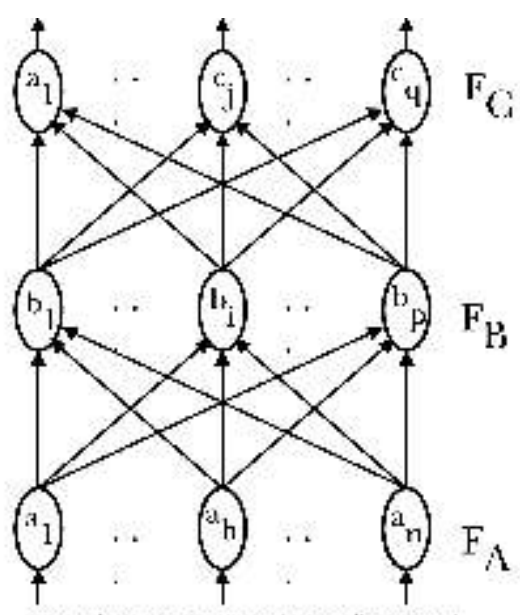

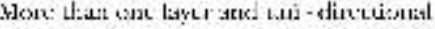

iii) La dinámica de activaciones queda determinada por la función: $f i(x j, w i j, \theta i)$.

iv) La dinámica de aprendizaje implica los cambios de estado de la red y comprende tres dinámicas posibles que corresponden a tres escalas temporales:

“a) Dinámica de los estados (escala temporal rápida). Corresponde a la activación de la red y equivale a un modo de recuerdo.

b) Dinámica de los parámetros (escala temporal intermedia) De escala temporal más lenta que la anterior, equivale a un modo de aprendizaje que implica una modificación en los parámetros de activación entre los nodos o intensidades de conexión).

c) Dinámica de grafo (escala temporal lenta) Es la más lenta de todas e implica la reconfiguración de la arquitectura de la red. (Vid idem). 


\section{Modelos mentales, elicitación y representación} del conocimiento judicial

Una de las conocidas características del conocimiento heurístico de un experto es el conocimiento compilado del cual el propio especialista no es consciente.

La elaboración de modelos mentales acerca del razonamiento judicial implica, por lo tanto, la realización de investigación cualitativa basada en la elicitación de dicho conocimiento.

Para la presente investigación se ha trabajado con una de las pocas jueces expertas en el país en materia de juicio penal oral, de reciente inclusión en nuestro sistema jurídico mediante reforma constitucional. ${ }^{9}$

Las técnicas de elicitación del conocimiento empleadas fueron las siguientes:

- Unestructured Interview: Usada al inicio de las sesiones para realizar una primer toma de contacto con los procesos de razonamiento del juez.

- Shadowing Self: Comentarios realizados por la juez al analizar las videograbaciones de sus propios juicios y explicar en voz alta los procesos que estaban ocurriendo en su mente en ese momento.

- Interruption Analysis: Identificación de puntos de interés por parte del investigador durante el shadowing self y realización de preguntas en profundidad.

- Mind Maps: Consistentes en la elaboración de dos clases de mapas: los realizados por la propia juez y los realizados por el investigador a efecto de reconstruir alguna explicación en formato teórico y someterlo a la entrevistada para sucesivas rectificaciones hasta el punto de aprobar una representación acertada.

9 Agradezco a la licenciada Alejandra Ramos, directora del Centro de Capacitación Judicial de Chihuahua por compartir su valioso conocimiento heurístico para esta investigación. 
Del análisis de la información obtenida surgió la idea de emplear una red neuronal artificial como metáfora teórica del modelo mental judicial que se presenta a continuación.

\section{El Modelo Mental Judicial (MMC)}

Como se ha indicado previamente, el modelo mental conexionista del razonamiento judicial constituye una metáfora teórica de segundo orden, en el sentido de que se basa fundamentalmente (aunque no únicamente) en la metáfora teórica de las redes neuronales artificiales que, a su vez, se basa en la teoría de las redes neuronales biológicas. La razón de ello, es que la teoría de las redes neuronales artificiales constituye un modelo simplificado (respecto de las biológicas) útil para las finalidades teóricas de este trabajo.

La caracterización de MMC es la siguiente:

El sistema neuronal corresponde al espacio mental de un operador jurídico experto, cuyos sensores están constituidos por los órganos sensoriales y los efectores por sus conductas motoras, fundamentalmente correspondientes a conductas verbales de tipo performativo.

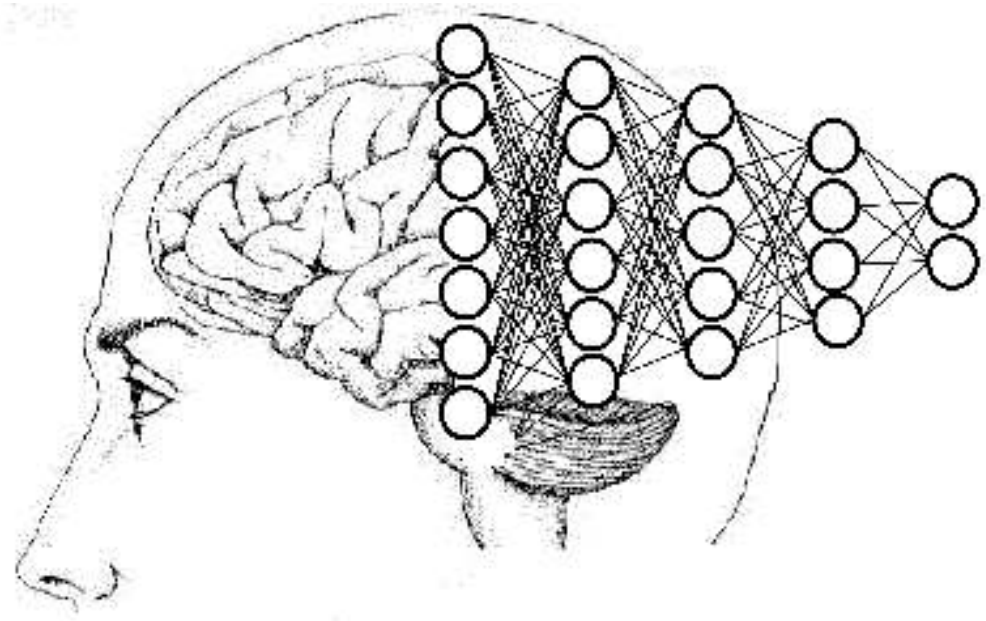


La definición de la red queda configurada de la siguiente manera:

i) Neuronas:

Conceptos pertenecientes a las siguientes clases: narrativas, evidencias, tipo penal, excluyentes de responsabilidad, teoría general del delito, decisión final.

La relación de este punto con la teoría conexionista de la memoria humana estriba en considerar que dichos conceptos supervienen a patrones de conectividad neuronal.

ii) Patrón de conectividad o arquitectura:

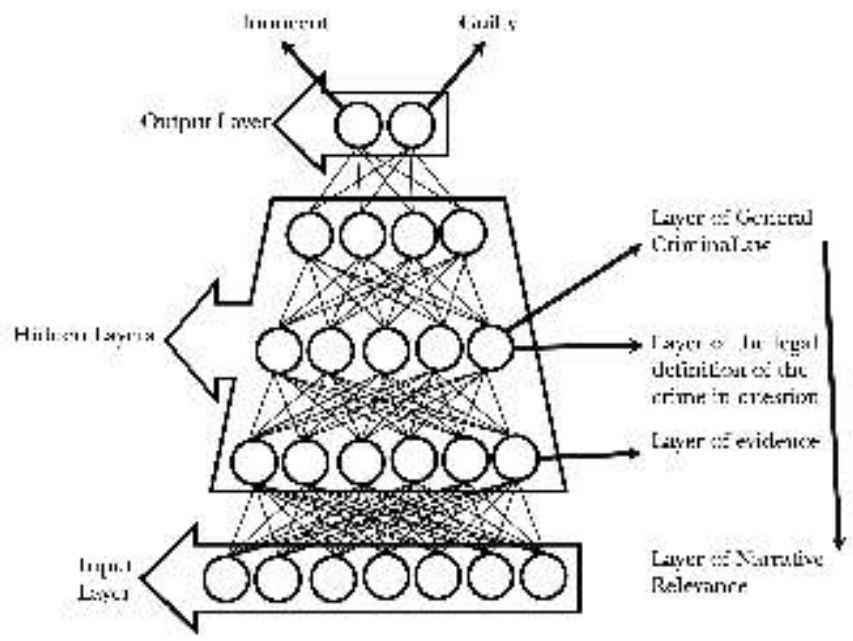

A) Una red multicapa con capas ocultas.

B) Una capa de entrada que corresponde a los términos de la narrativa del caso, considerados jurídicamente relevantes por el operador jurídico.

C) Una capa de salida constituida por dos neuronas de activación binariamente excluyentes: "Responsable", "no responsable".

D) Una capa oculta de proximidad inmediata a la capa de entrada correspondiente a los conceptos de evidencias.

E) Una capa oculta de jerarquía superior a la capa de las evidencias correspondiente a las propiedades definitorias del tipo penal. 
F) Una capa oculta de jerarquía superior a la capa del tipo penal correspondiente a los conceptos eximentes de responsabilidad consistentes con el tipo penal en cuestión.

G) Una capa oculta de jerarquía superior a la relativa a eximentes de responsabilidad correspondiente a los conceptos de la teoría general del delito.

H) Las conexiones pueden ser bidireccionales, intercapa e intracapa, y retroalimentativas. La densidad de la conectividad es alta y opera entre todas las capas.

iii) Dinámica de activaciones:

Se asume que la activación de las diferentes neuronas opera en función de la satisfacción de un umbral de estado activo que equivale a un estado de certeza o creencia heurística. Se asume también que la intensidad de las conexiones entre las neuronas no opera de manera determinista, sino de manera difusa o plausibilista. En el modelo se asumen tres grados de intensidad representados con diferentes colores: bajo (amarillo), medio (naranja) y rojo (equivalente a la satisfacción del umbral y correspondiente activación de la neurona o neuronas). Las conexiones sinápticas pueden ser excitativas o inhibitorias.

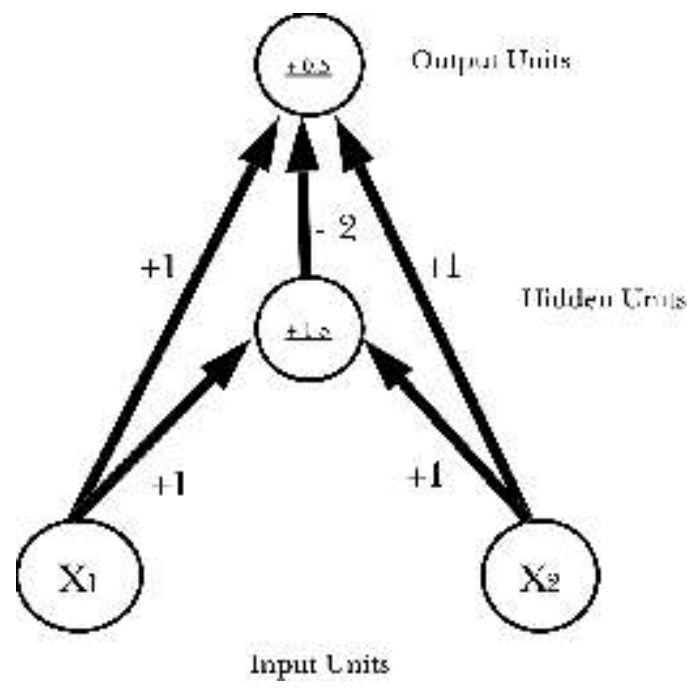


iv) La dinámica de aprendizaje implica los diferentes cambios en la configuración de la red en el eje diacrónico correspondiente al proceso judicial. Implica una dinámica de estados que corresponde a la activación de patrones de conectividad en la memoria al contacto con el medio (el caso). Y una dinámica de parámetros derivada de las modificaciones de valores asignados a los diferentes conceptos a lo largo del proceso.

Time line of the Judicial Mental Model

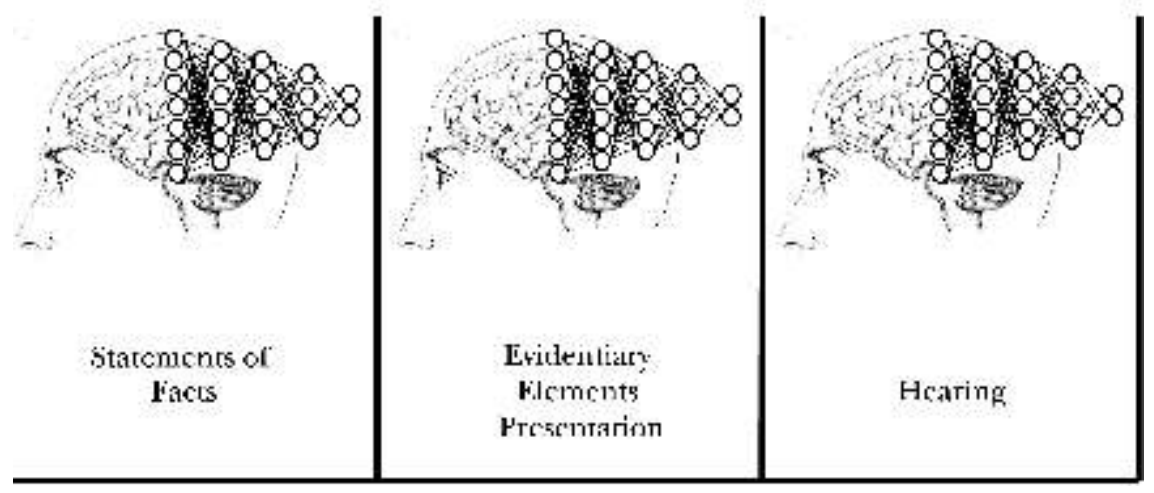

Se excluye una dinámica de grafo del modelo, por suponer que requeriría de una reforma legislativa.

v) Entorno de operación: El juzgado y los inputs de los casos, con una dimensión básicamente narrativa (la o las historias del caso presentadas por las partes, los testigos, los dictámenes periciales, etcétera).

A continuación, tenemos un ejemplo de cómo funcionaría el Modelo Mental Judicial. 


\section{EL CASO HATTORI}

Hattori, un estudiante japonés de 17 años de edad, quien se encontraba realizando una estancia de intercambio con la familia Haymaker, junto con Haymaker Junior fueron invitados a una fiesta de Halloween organizada por sus compañeros de la preparatoria.

En la tarde del sábado 17 de octubre de 1992 los dos adolecentes se dirigieron a Baton Rouge (donde habría de llevarse a cabo la fiesta). Hattori se disfrazó de "John Travolta", mientras que Haymaker Junior simulaba estar herido del brazo y se había pintado heridas con sangre en el rostro.

No se dieron cuenta de que tenían la dirección equivocada hasta que fue demasiado tarde. Así, llegaron a la casa de la familia Peairs pensando que el evento tendría lugar en dicha casa.

La familia Peairs estaba constituida por Rodney (el esposo), Bonnie (la esposa), y por sus hijas Brittany y Stacey, de 11 y 7 años respectivamente.

Haymaker Junior tocó el timbre. Cuando Bonnie abrió la puerta, sólo podía ver a Junior, pero al girar su cara y ver a Hattori, con una expresión de terror inmediatamente azotó la puerta sin dejar que los jóvenes explicaran el motivo de su presencia.

Después de cerrar la puerta, Bonnie lanzó un grito frenético a Rodney pidiendo que bajara inmediatamente. Rodney, que se encontraba en el piso superior, bajo enseguida con un arma. Mientras tanto, Bonnie tomó a sus dos hijas y se dirigió al cuarto trasero debajo de las escaleras con la intención de llamar a la policía.

Al bajar por la escalera, Rodney podía escuchar los gritos de su esposa. Cuando por fin llegó a la habitación en que se encontraban Bonnie y sus hijas, pudo observar que estaban muertas de miedo. Rodney y Bonnie se miraron por unos segundos, y sin mencionar palabra alguna, Rodney se dirigió hacia la puerta. 
Bonnie no hizo la llamada telefónica que tenía en mente. Le pidió a sus hijas que se quedaran en el cuarto, se levantó apresuradamente y alcanzó a su marido en su camino hacia la entrada de la casa.

En su camino hacia la puerta, Rodney tomó una de sus múltiples armas que estaban desperdigadas por toda la casa. Se trataba de una pistola tipo Magnum 44 que, de hecho, ya se encontraba cargada. Antes de abrir la puerta, ya le había quitado el seguro a la pistola y estaba listo para usarla a la menor provocación.

Sin intercambiar opinions con su esposa acerca de qué era lo que había visto que la espantó tanto, ambos abrieron finalmente la puerta.

Hattori y Haymaker Junior ya estaban retirándose después de lo que para ellos fue una reacción incomprensible por parte de Bonnie.

Cuando escucharon que la puerta se abría, se dieron la vuelta. Hattori comenzó a caminar hacia la pareja diciendo "he venido a la fiesta". Haymaker Junior sospechaba que algo andaba mal y le gritó a Hattori pidiéndole que se detuviera, pero aquél no le hizo caso, dado que no pensaba que se encontraba en alguna clase de peligro y en vista de que sólo quería preguntar por la dirección correcta.

Rodney gritó: "Freeze" (que en inglés tiene la connotación local de "detente o disparo"). Dado que Hattori llevaba poco tiempo inmerso en la cultura norteamericana, no comprendió el sentido de la instrucción y siguió su paso.

Cuando Hattori se encontraba a unos dos metros de distancia, Rodney levantó su arma y le disparó al adolecente en el pecho, provocándole la muerte.

El entorno de operación se constituye por diversos inputs correspondientes a las narrativas de diferentes partes en el proceso: el presunto responsable, su esposa, el amigo de Hattori, testigos, etcétera. 


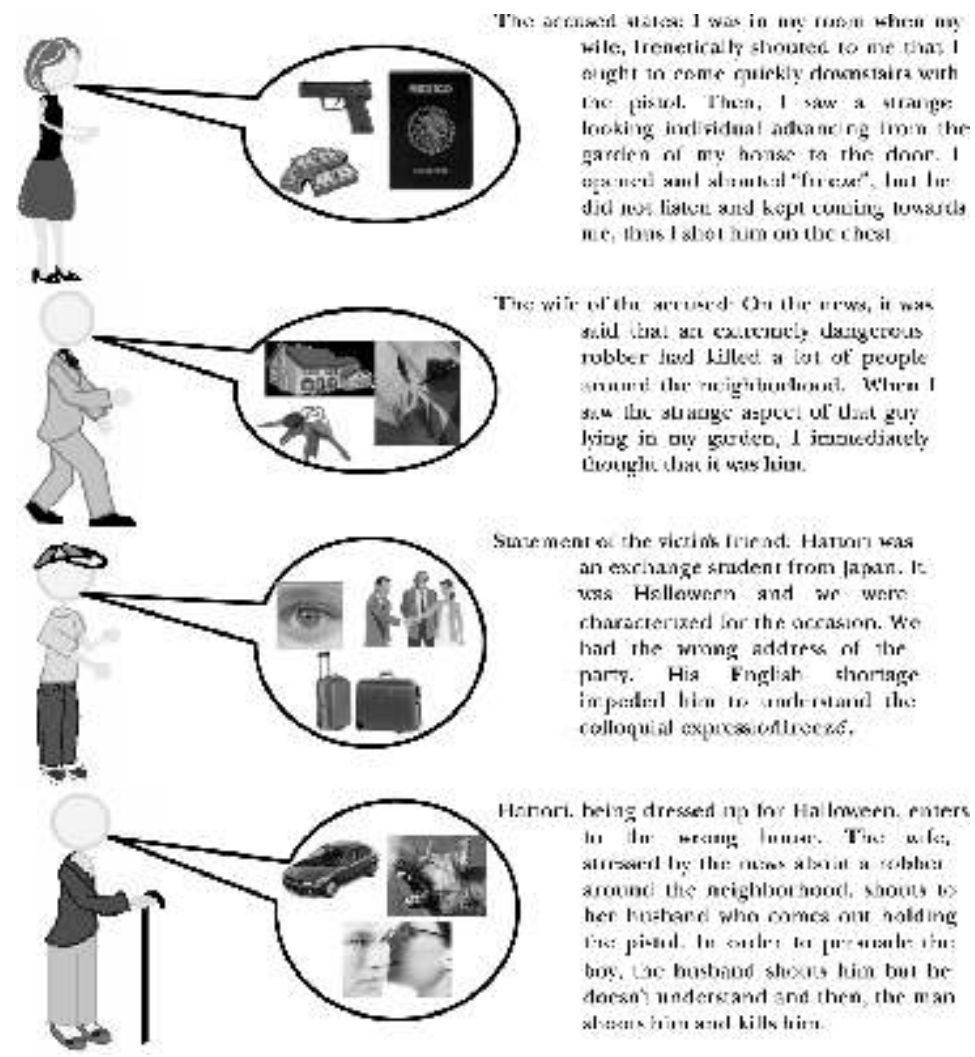

Cada una de las partes involucradas declara lo siguiente: $\mathrm{El}$ acusado (Rodney) sostiene: "Estaba en mi cuarto cuando mi esposa gritó en forma frenética que bajara con un arma. Después vi a un tipo de apariencia extraña aproximándose a nosotros a través de nuestro patio. Abrí la puerta y le grité que se detuviera, pero no hizo caso y continuó acercándose con paso amenazante. Por ello le disparé, pensaba que mi familia estaba en un grave peligro".

La esposa del acusado declara que: "En las noticias había escuchado que un asaltante muy peligroso de apariencia oriental había asesinado a alguna persona del vecindario. Cuando abrí la puerta esa noche y vi a este tipo con vestimenta rara y al otro chico sangrando, pensé que se trataba de la persona de la que hablaban en los noticieros". 
Declaración del amigo de la víctima: "Hattori era un estudiante de intercambio que venía de Japón. Nos habian invitado a una fiesta de Halloween, y como suele ser el caso en este tipo de fiestas, decidimos disfrazarnos para la ocasión. Teníamos la dirección equivocada. Con su limitada comprensión de los regionalismos de nuestra cultura, Hattori no entendió lo que el señor Peairs quiso decir con "Freeze»".

A continuación, el juez reconstruye el caso con los elementos anteriormente expuestos al efecto de producir una narrativa coherente.

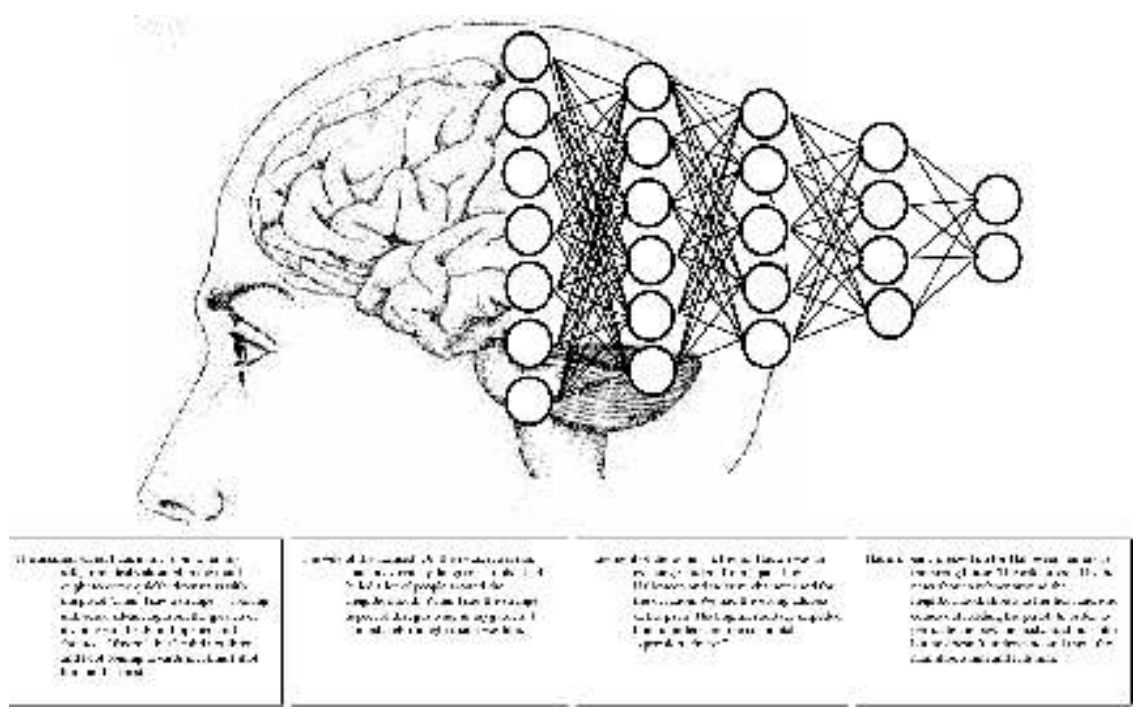

Como digresión vale especificar que a efecto de evitar complicaciones innecesarias, hemos considerado un ejemplo sencillo que no presenta el problema de dos o más ver- 
siones de hechos que puedan explicar las mismas evidencias. Sin embargo, se hace notar que este problema, de particular relevancia en el terreno de la inteligencia artificial y el derecho queda ubicado en esta parte del modelo.

Los elementos de la narrativa reconstruida jurídicamente relevantes y por tanto que activan la capa de entrada, son los siguientes:

Elementos discursivos relevantes:

1. El acusado dispara y provoca la muerte de Hattori

2. Hattori se encontraba en propiedad ajena sin permiso

3. Hattori tenía un aspecto amenazante

4. Hattori no hizo caso a la instrucción de detenerse

Como resultado de la activación de la capa de entrada (hechos relevantes), se activa un patrón de conectividad de la capa de entrada a las capas correspondientes al tipo penal o definición de delitos (posible homicidio), pero también a la capa correspondiente a las eximentes de responsabilidad (posible legítima defensa) en conexión con los hechos relevantes 2,3 y 4. La intensidad de la conexión es de un valor de plausibilidad bajo.

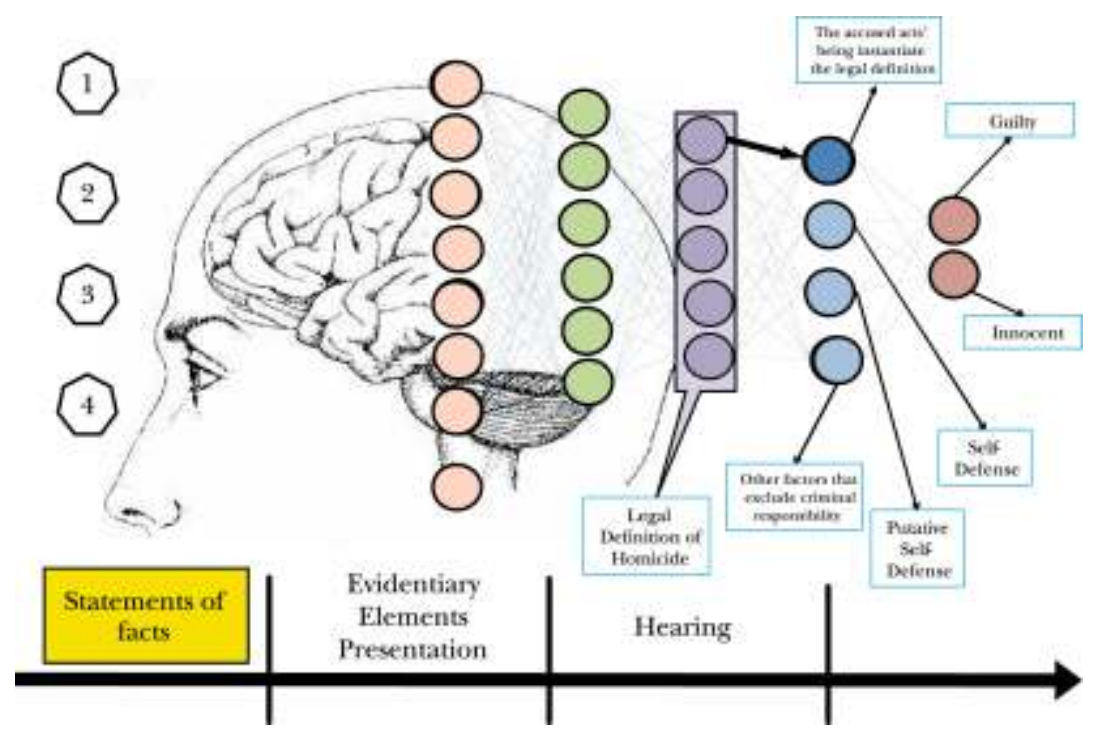



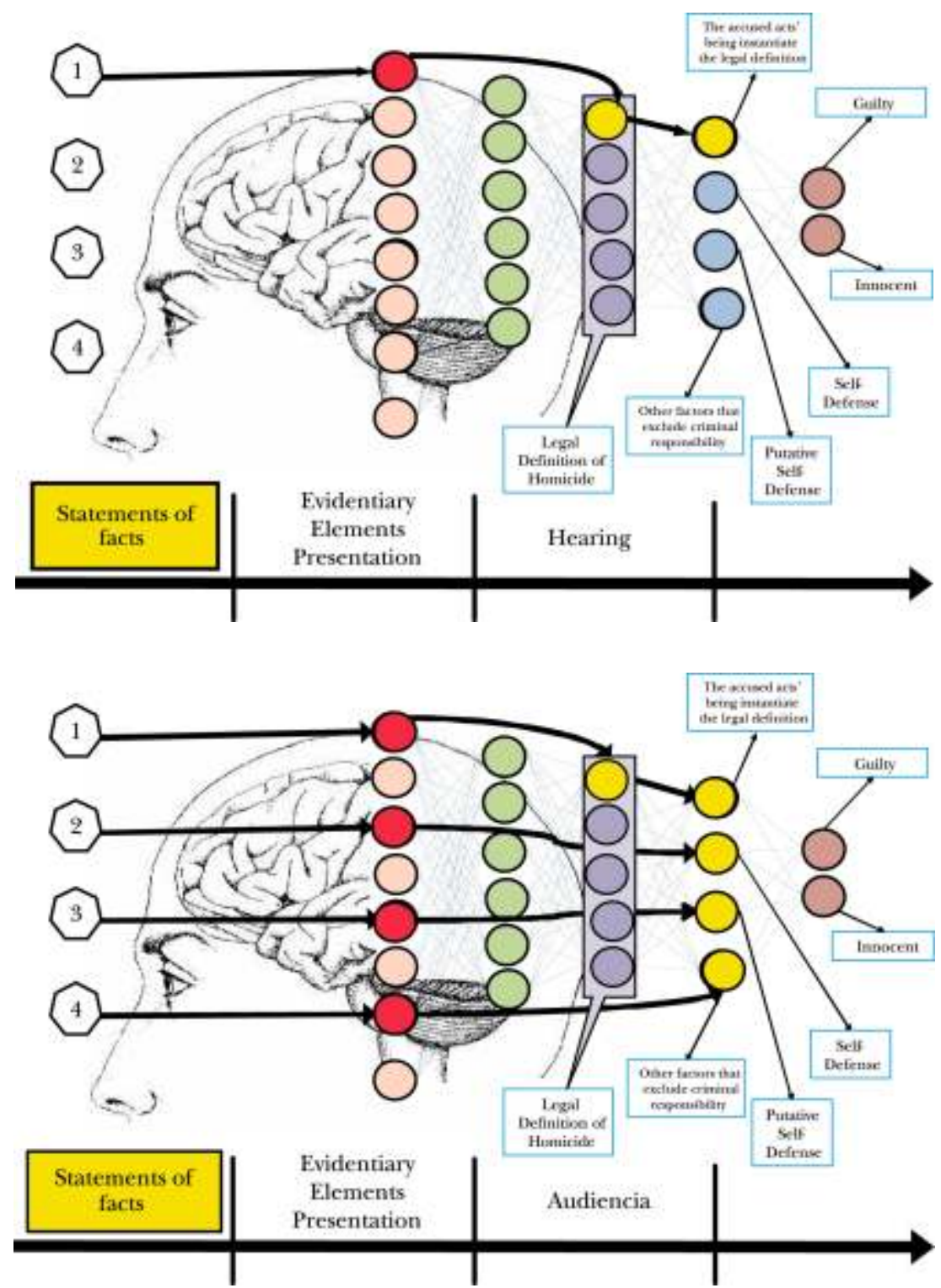

Dado que el tipo penal de homicidio instancia al concepto teórico del delito, se activa esta neurona en la capa correspondiente. 
Durante la etapa probatoria se presentan los siguientes inputs:
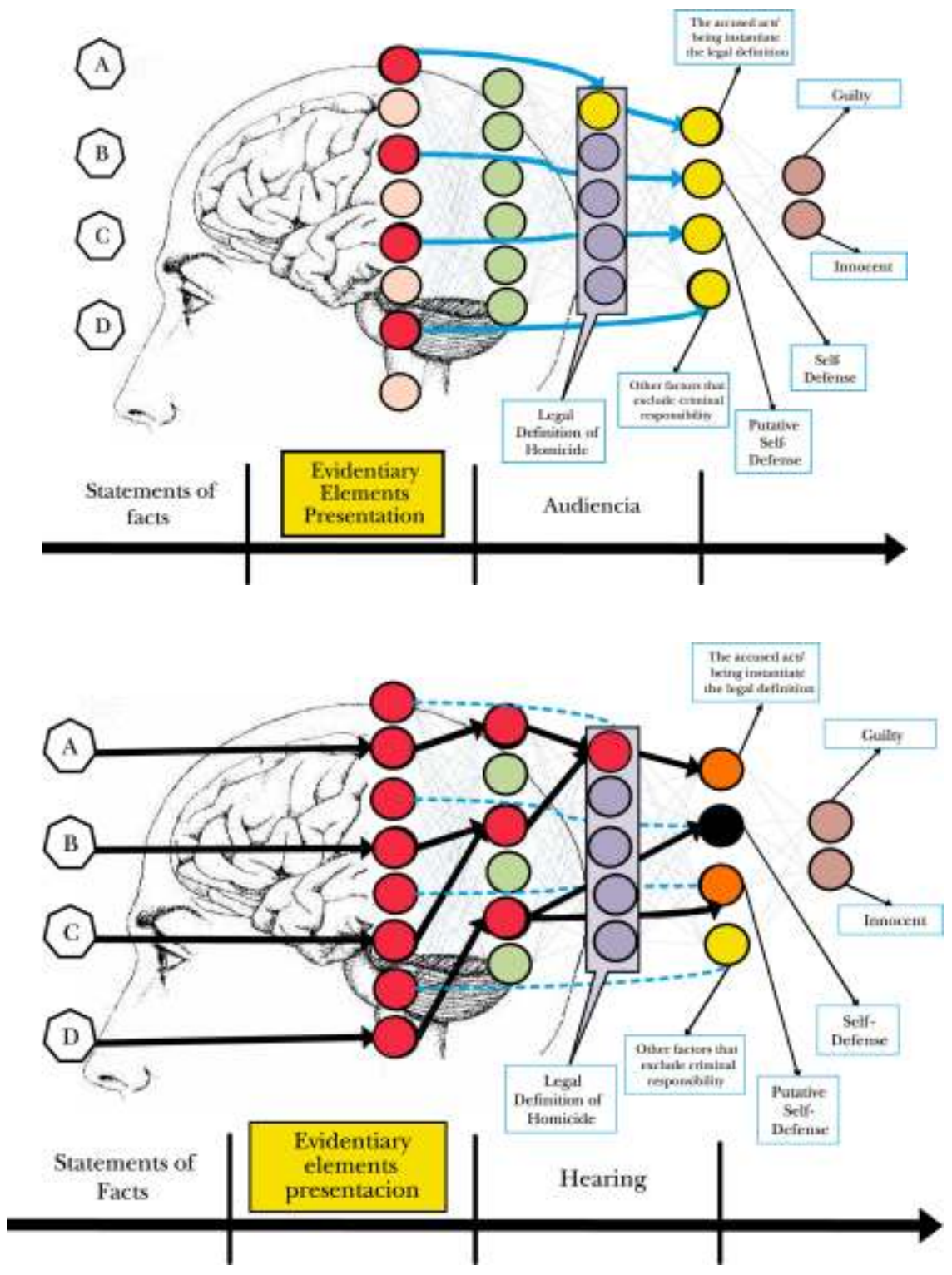
Estas pruebas activan la segunda capa oculta. Corresponden a las pruebas confesional y dos periciales.

$\mathrm{El}$ reforzamiento de las pruebas (peso excitativo) aumenta la intensidad de la conexión en la segunda capa oculta, se supera el umbral correspondiente y se activa la neurona correspondiente a la creencia justificada de que Rodney cometió el delito de homicidio. Sin embargo, debe destacarse que aún no alcanza el umbral requerido para activar la capa correspondiente a la teoría del delito, debido a que también están activas neuronas de la capa correspondiente a las excluyentes de responsabilidad por legitima defensa, aunque su peso sea bajo (inhibitorio).

Sin embargo, debe recordarse que también se cuenta con otra prueba $\mathrm{D}$, correspondiente a una testimonial presentada por el amigo de Hattori, en donde se indica que la víctima era un joven estudiante japonés (lo que neutraliza su posible peligrosidad), que no comprendía bien inglés (lo cual explica porque continuó caminando no obstante la advertencia) y que se habian equivocado en la dirección de la casa de la fiesta de Halloween (lo que explica porque había entrado con tanta confianza a la casa de los Peairs).

Estos elementos generan un patrón de conectividad intercapa hacia la neurona correspondiente a la legitima defensa con peso inhibitorio y por tanto hacen que se desactive la creencia en una posible legitima defensa objetiva.

No obstante, la capa correspondiente a las eximentes de responsabilidad sigue activa con un nivel de plausibilidad bajo, debido a una posible legitima defensa subjetiva (putativa) i.e., que el homicidio hubiera sido resultado de una insuperable creencia subjetiva de que se estaba ante una agresión real, con un peso de plausibilidad medio.

Pero entre las pruebas recibidas se cuenta con otras dos: 

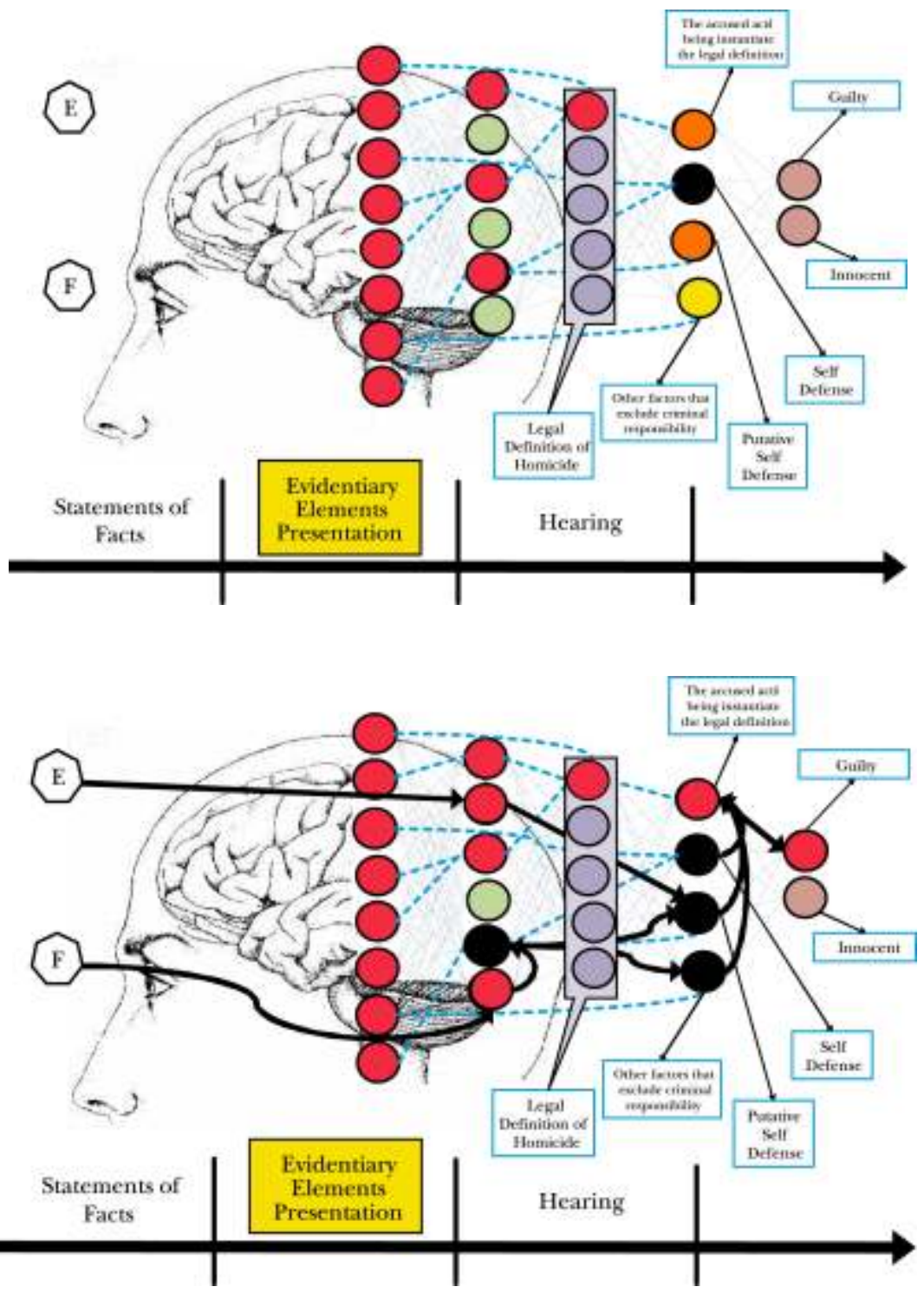

"E" es una testimonial que indica que Hattori no avanzaba de modo amenazante, sino más bien alegre, y que su disfraz no llevaba a confundirlo con un sujeto peligroso, pues estaba vestido de John Travolta. 
"F" es otra testimonial que afirma que Hattori había avanzado apenas dos pasos en el jardín.

Las neuronas activadas con estos elementos generan un patrón de conectividad con peso inhibitorio respecto a la neurona correspondiente a la eximente de responsabilidad por legitima defensa subjetiva que pasa a estado de desactivación y junto con ella toda la capa de excluyentes de responsabilidad. En este estado, se transfiere el peso inhibitorio a toda la capa correspondiente a delito injustificado, alcanzando el umbral requerido para cambiar estado activo. Este estado genera un nuevo y último patrón de conectividad hacia la capa de salida que activa la neurona correspondiente al estado de "responsable" que activa los mecanismos efectores del sistema y una correspondiente conducta motora, que en este caso corresponde a la emisión de una sentencia con efectos performativos que cambian el estado de cosas del entorno de operación, construyendo una nueva realidad jurídica.

\section{DISCUSIÓN}

El modelo mental conexionista del razonamiento judicial proporciona una explicación descriptiva de los procesos cognitivos de los jueces.

Sobre la base de este modelo es posible realizar una evaluación del derecho penal a partir del grado de satisfacción de las exigencias epistemológicas de todo sistema de investigación tendente a la obtención de creencias verdaderas. Una evaluación de este tipo parece más fructífera que la limitarse a consideraciones pre-legislativas acerca de cómo podría generarse dicho sistema de investigación en el derecho, en abstracto.

El modelo también pone de relieve que las expresiones vagas empleadas por las reglas de adjudicación deben ser entendidas bajo una óptica sistemática y no como expresiones huérfanas de contexto. Dichos términos parecen denotar estados de clausura cognitiva de modelos mentales que presuponen muchos procesos complejos en cuya operativi- 
dad holística radica su racionalidad. En algún sentido, son equivalentes a la expresión "jaque mate" carente de sentido sin la función constitutiva de sus reglas y el estado final de ciertos modelos mentales generados con base en esas mismas reglas.

Otra ventaja de MMC es que permite ver con claridad que las discusiones acerca de narrativas enfrentadas en el derecho propias de la IAD distorsionan y ocultan procesos sumamente complejos que van más allá de la mera dialógica entre las narrativas mismas. Muchas de sus generalizaciones solo tienen sentido en el complejo mecanismo de equilibrios reflexivos representados en las distintas capas del sistema.

De igual manera MMC proporciona un contexto holístico amplio en el que las discusiones sobre narrativas enfrentadas ocupan su lugar, al menos en la tradición romano germánica. El carácter holístico de MMC supera las simplificaciones del paradigma atomista de las pruebas y es compatible tanto con la lógica de la evidencia (incluyendo un lugar para parámetros, factores y critical questions) y con la lógica no monotónica, dado que una red neuronal también puede operar como máquina de Turing y puede representar las operaciones lógicas. El recurso de umbrales de diferentes grados hace posible pensar en aplicaciones con lógica difusa.

A través de MMC se refuerza la idea de que el razonamiento judicial puede ser explicado con mayor claridad desde un modelo constructivista, coherentista y conexionista. La dinámica de estados de las redes de MMC muestra la constante búsqueda por la coherencia en el razonamiento judicial. Sin embargo, muestra también que, a diferencia de lo que puede suceder con los jurados, en quienes juegan un papel primordial las creencias comunes o representaciones sociales generales. En el caso del derecho romano germánico y el sistema de creencias que lo constituyen, se producen modelos mentales con características particulares. 


\section{FUTURAS INVESTIGACIONES}

En este trabajo se ha presentado una versión simplificada de las redes en la que no se incluyen muchos elementos relevantes para la epistemología jurídica y el derecho procesal. Sin embargo, parece plausible poder ubicar en la topología de MMC elementos tales como el estándar de prueba como una capa intermedia a la capa de salida con un umbral equivalente al grado de exigencia del propio estándar.

De la misma manera se contempla como una posibilidad incluir en MMC otros conceptos empleados por el legislador para fijar el estándar de prueba, tales como las presunciones o cargas probatorias, representables como pesos por default, etcétera.

En el terreno de la computación, puede servir como guía para la arquitectura de tres tipos de sistemas: un sistema elicitador del conocimiento experto de los jueces que permita elaborar modelos tanto cualitativos como cuantitativos de casos y estrategias de solución (elaboración de escenarios tipo Expertius); un segundo modelo podría ser un sistema experto (Expertius In) para la ayuda a la decisión judicial con base en MMC, y uno tercero para la enseñanza judicial on line.

En el ámbito de la enseñanza del derecho MMC es compatible con las teorías pedagógicas orientadas al aprendizaje complejo. Particularmente con aquellas que asumen, al igual que en este trabajo, al paradigma de los modelos mentales complejos como punto de partida. El hecho de haber identificado diferentes clases de conceptos, los patrones de conectividad que los vinculan y su dinámica de operaciones coincide con la clasificación de los modelos mentales propuesta por Sandra Castañeda y el modelo C4/ID. Las futuras investigaciones en esta línea podrían consistir en la identificación de las tareas cognitivas y las competencias requeridas para desempañarlas en cada una de las capas de la red, así como las estrategias pedagógicas adecuadas para inducirlas. 
IX. JUSTIFICACIÓN SOCIAL

Una coyuntura que hace especialmente atractivo trabajar en esta línea en México corresponde a las recientes reformas constitucionales que incluyen en el país el juicio penal oral como una estrategia para acabar con una larga y negra historia de corrupción e impunidad en las instituciones judiciales de derecho penal. En este momento se cuenta con un puñado de jueces con la experiencia suficiente para elicitar su conocimiento y representar sus modelos mentales con base en MMC y aprovechar las ventajas de la enseñanza en línea para generar cursos de capacitación en todo el país. Tenemos ocho años para incorporar la reforma en todos los estados; pero si no se toma conciencia de que el derecho se construye a partir de procesos psico-cognitivos y no de enunciados muertos, volveremos a repetir la historia y dejaremos que otros modelos mentales sigan construyendo una realidad social no deseada desde una de las instituciones fundamentales para comprender y justificar al derecho: las instituciones judiciales. 